\title{
Subsidies promote use of drought tolerant maize varieties despite variable yield performance under smallholder environments in Malawi
}

\author{
Stein T. Holden ${ }^{1}$ (D) Monica Fisher $^{2}$
}

Received: 11 February 2015 / Accepted: 29 September 2015 / Published online: 2 November 2015

(C) The Author(s) 2015. This article is published with open access at Springerlink.com

\begin{abstract}
This study used a three-year panel dataset for 350 Malawian farm households to examine the potential for widespread adoption of drought tolerant (DT) maize varieties, a technology that holds considerable promise for helping smallholder farmers in Sub-Saharan Africa (SSA) adapt to drought risk. Regression results revealed that DT maize cultivation increased substantially from 2006 to 2012, with the main driver being the Malawi Farm Input Subsidy Program. Recently experienced drought and farmer risk aversion stimulated adoption of DT maize. In yield performance, improved maize varieties performed significantly better than local maize during the 2011/12 drought year. However, DT maize did not perform significantly better than other improved maize varieties used in Malawi, which is in contradiction to results obtained from on-station and on-farm trials. A plausible explanation is that the severe drought in Malawi in the 2011/12 season occurred early in the rainy season and DT maize primarily provides an advantage in the case of late droughts during the silking/grain filling stage of the crop. Preliminary results herein suggest that it was lack of rainfall in December 2011 that constrained maize yield while rainfall in January and February was less limiting. Additionally, the length of the longest dry spells in December and February further strengthens the evidence in favor of this explanation, but further research is needed to reach a conclusion.
\end{abstract}

Stein T. Holden

stein.holden@nmbu.no

Monica Fisher

monica.fisher@oregonstate.edu

1 School of Economics and Business, Norwegian University of Life Sciences, P.O. Box 5033, 1432 Ås, Norway

2 Applied Economics Department, Oregon State University, 213 Ballard Extension Hall, Corvallis, OR 97331, USA
Key words Improved maize varieties $\cdot$ Drought $\cdot$ Drought tolerance · Timing of drought $\cdot$ Input subsidies $\cdot$ Maize yields . Agricultural adaptation $\cdot$ Risk aversion

JEL classification $\mathrm{Q} 12 \cdot \mathrm{Q} 18$

\section{Introduction}

Agricultural development in sub-Saharan Africa (SSA) faces unprecedented challenges due to changes in demand for food, market conditions and climate. The Intergovernmental Panel on Climate Change (Intergovernmental Panel on Climate Change (IPCC), 2014) predicts that, under medium scenarios, mean annual temperature over extensive areas of Africa will be $2{ }^{\circ} \mathrm{C}$ higher during the middle of the 21 st Century than during the late 20th Century. Despite uncertainty about future changes in rainfall in SSA (Intergovernmental Panel on Climate Change (IPCC), 2014), climate change models consistently predict increased incidence of drought ( $\mathrm{Li}$ et al., 2009). Increasing temperatures and changes in precipitation are expected to adversely affect biodiversity, amplify existing stress on water supplies, exacerbate the vulnerability of agricultural systems, and increase the burden of a range of climate-related health outcomes (Intergovernmental Panel on Climate Change (IPCC), 2014).

Climate change is not being superimposed on a static world (Burke \& Lobell, 2010). African farmers already adapt to climate variability by switching to different crops and by diversifying their cropping systems (Deressa et al., 2009); by selling physical assets, such as livestock (Kinsey et al.,1998); by migrating to gain access to land or employment (Dillon et al., 2011); by diversifying into non-farm wage employment (Porter 2012); and by increasing their reliance on natural resources (Fisher et al., 2010). However, in some parts of SSA, 
the magnitude and speed of the predicted climate changes are likely to outstrip the local efforts to manage those changes, and large public and private investments in crop breeding, irrigation infrastructure, and safety nets (e.g., micro-insurance) are needed to meet the food needs of the growing human population (Burke \& Lobell, 2010).

The present paper focuses on recent advances in maize research that hold promise for helping African farmers adapt to drought. Maize is the most important food crop in SSA, where it is almost completely rainfed and, therefore, dependent on the region's increasingly erratic precipitation. Around $40 \%$ of Africa's maize-growing area faces occasional drought stress in which yield losses are $10-25 \%$. Around $25 \%$ of the maize crop suffers frequent drought, with losses of up to half the harvest (CIMMYT, 2013). To reduce vulnerability and improve food security, the Drought Tolerant Maize for Africa (DTMA) project has made releases of more than 160 drought tolerant (DT) maize varieties between 2007 and 2013.

DTMA varieties have been bred using modern conventional methods, without genetic modification technologies. DT maize varieties can produce about $30 \%$ of their potential yield after six weeks of water stress, before and during flowering and grain-filling stages (Magorokosho et al., 2010). In addition to being drought tolerant, many of these varieties have additional traits that make them attractive to growers, such as resistance to major diseases, nitrogen use efficiency, and high protein content. The DT varieties have not, however, been bred for some traits that studies have revealed are important to Malawian smallholders, such as poundability and storability (Lunduka, Ricker-Gilbert, \& Fisher, 2013). In a recent survey related to DT maize adoption in Malawi, farmers complained about poor storability of the DT maize varieties, i.e. the farmers were concerned the varieties are prone to attack by storage pests such as weevils (Fisher et al., 2015). DT maize varieties have similar labor requirements and seed costs to those of non-DT commercial varieties.

The new DT maize varieties underwent extensive multilocation on-farm testing using a participatory variety selection approach with farmers. On-farm trials across sites in eastern and southern Africa, including Malawi, revealed that DT maize varieties out-yield popular commercial checks by 83 $137 \%$ (controlled drought), 26-47\% (random drought), and 25-56\% (optimal rainfall conditions) (Unpublished data from Tsedeke Abate, DTMA Project Leader, March 2015). The yield advantage of the new DT maize varieties over local varieties of maize is expected to be even greater than these latter figures. Research across eastern and southern Africa has indicated a consistent yield advantage of improved maize varieties over local maize varieties at different levels of fertilizer use and various soil fertility and rainfall conditions (Smale \& Jayne, 2003).

In Malawi, as in the other 12 DTMA countries (Angola, Benin, Ethiopia, Ghana, Kenya, Mali, Mozambique, Nigeria,
Tanzania, Uganda, Zambia, and Zimbabwe), seed delivery has been the responsibility of national agricultural research systems and public and private seed companies. To diffuse information on the new DT varieties, the DTMA project has used extensive field demonstrations and field days. Messages have been channeled via posters, radio and television broadcasts and newspapers. In 2013 alone, more than 33,000 MT of seed was delivered to farmers in the 13 SSA countries (DTMA 2014).

The potential higher yields of DT maize can substantially benefit smallholder farm households in SSA, through improved food security and increased net returns. By decreasing the vulnerability of farm households to drought-related harvest failure, DT varieties also reduce the need for harmful post-failure coping strategies, such as borrowing, reducing food consumption, sale of household assets, or taking children out of school. Two recent assessments of DT maize adoption in Africa, based on the economic surplus method, predicted large positive impacts of increasing average yields and reducing yield variability. Kostandini et al. (2013) estimated that, by 2016, adoption of DT maize could generate between US $\$ 362$ million and US $\$ 590$ million in cumulative benefits to producers and consumers in the 13 DTMA project countries. For the same countries, La Rovere et al. (2014) estimated economic benefits of US\$907 million under conservative yield gains, and US\$1535 million under optimistic yield gains.

The present study addresses two knowledge gaps related to the potential of DT maize for drought risk mitigation in SSA. First, there has been insufficient research on demand for DT maize. The realization of expected benefits of DT maize depends on adoption of the new DT maize varieties by SSA farmers, which has only been investigated in two studies thus far (Fisher et al., 2015; Tambo \& Abdoulaye, 2013). These studies suggest considerable farmer demand for DT varieties in Malawi and Nigeria, but the wider literature on adoption of improved crop varieties by smallholder farmers in SSA indicates an uneven record: incidents of widespread adoption (Alene et al., 2009) are mixed with examples of low rates of adoption and lack of sustained use of seemingly advantageous farm technologies (Kijima et al., 2011; Suri, 2011).

By 2011, the year of the present study, 16 DT maize varieties had been released to Malawian farmers. Of these, eight were developed under the DTMA project and bred for drought tolerance: Chitedze4 (released in 2009), CAP9001 (2009), MH27 (2010), MH28 (2010), PAN53 (2008), SC719 (2008), ZM309 (2009), and ZM523 (2009). The remaining eight DT maize varieties - MH26 (2007), PHB30G19 (2006), SC403 (1999), SC627 (2000), ZM421 (2001), ZM521 (2001), ZM621 (2000), and ZM623 (N/A) - were developed outside the DTMA project but have been characterized as drought tolerant by maize breeders. It should be mentioned that the statistics for the yield advantage of DT 
maize varieties over popular commercial checks provided earlier in the Introduction concern only the DTMA project varieties.

Cultivation of the DT maize varieties by smallholder farmers has been viewed by Malawi observers as a way to free land for other crops, thereby promoting crop diversification, reduce the impact of drought, and increase farmer market participation. Our survey data show that four of the released DT maize varieties were cultivated by the farmers sampled. We assessed demand for these varieties and estimated regression models to reveal the determinants of DT maize uptake ${ }^{1}$ in Central and Southern Malawi. Our study, similar to the work of Jain et al. (2015), employed a modeling approach that accounted for the many factors that simultaneously influence a farmer's decision to cultivate DT maize, an approach rarely used in the adaptation literature. In particular, we assessed how the following correlated with DT maize uptake: availability of DT maize varieties through the input subsidy program (FISP), knowledge disseminated through the extension system, access constraints, exposure to recent droughts, and risk aversion.

A second knowledge gap we addressed is that although the yield advantage of DT maize for African farmers has been repeatedly predicted from on-station and on-farm trials (e.g., Magorokosho et al., 2010; Setimela et al., 2012), these trials ranged from highly to moderately controlled settings and did not sufficiently replicate farmer conditions. Furthermore, the number of farmers in the trials has been small, for example only 49 households across eight countries in Setimela et al. (2012), and farmers were chosen by extension agents and may therefore represent progressive rather than average farmers. Our 2011/12 data for 350 farm households in six Malawi districts allows us to compare the yields of DT maize varieties, other improved maize varieties, and local maize varieties under a range of farmer characteristics, farmer management, agro-ecologies, and drought vs. non-drought conditions. In particular, we assessed performance of the DT and other maize varieties under the unusual rainfall conditions of 2011/12: a severe dry spell early in the rainy season (December drought), with some of the study areas also experiencing a less severe dry spell in February (during maize silking/grain filling). It is the latter type of drought that DT maize has been bred for, while less is known about its performance under droughts occurring early in the rainy season. Monthly rainfall for December, January and February and length of the longest dry spell in December and February were included to compare the maize varieties.

\footnotetext{
${ }^{1}$ We distinguish between uptake and adoption, as availability of free seeds or non-availability of certain varieties can give a distorted picture of adoption. We define adoption as a more long-term preferred response of farmers facing market prices for seeds but no other access constraints.
}

As highlighted by Jain et al. (2015), a limitation of previous research is the common assumption that any weather-induced change made by farmers and other decision makers is adaptive or beneficial. More research is needed to examine whether changes made by decision makers in response to climate variability are in fact beneficial to the individual and her/his household.

Malawi is a useful setting for the present study for several reasons: maize, the staple crop, has high importance for national and household food security, drought risk exhibits considerable spatial variability, and DT maize adoption has potential to bring about substantial reduction in food insecurity. Our study provides information on the likely effects of scaling up the distribution of DT maize varieties in drought and normal years, and helps to identify future priorities in crop breeding, agricultural extension, and infrastructure that hold promise for stimulating adoption. Furthermore, we assess how exposure to previous drought shocks and farmers' risk aversion affect adoption of DT maize.

\section{Data and study context}

\section{The farm household survey}

Data for this study come from a longitudinal farm household survey with an original sample of 450 households located in two districts in Central Malawi (Kasungu and Lilongwe) and four districts in Southern Malawi (Chiradzulu, Machinga, Thyolo and Zomba). Household interviews took place in 2006, 2007, 2009 and 2012. In 2006, households were randomly sampled within each Enumeration Area (EA) following the Integrated Household Survey of 2004, conducted by Malawi's National Statistical Office. Two (in Thyolo, Chiradzulu and Machinga districts) or three (Zomba, Kasungu and Lilongwe districts) EAs were randomly sampled and at least 30 households were randomly sampled from each of the EAs (Lunduka, 2009). In the 2012 survey, we found and re-interviewed 350 of the original households. As in the earlier years, the 2012 survey included collection of detailed farm plot level data with GPS-measurement of plot sizes. A plot was defined as a uniform crop stand that received homogenous "input treatment" (Holden \& Lunduka, 2012). Unlike the former large national surveys that typically collected data from one plot per household and relied on farmers' estimates of plot size and farm size, we measured (with GPS) and collected data for all plots of the sample households. Our data should therefore suffer less from measurement error in these variables than the past larger surveys.

In this study we present results based on the three-year panel $(2006,2009,2012)$ as well as expanded models for 2012. The 2012 data includes several important variables not part of the earlier datasets, including those related to DT 
maize adoption and a substantial amount of recall information from the 2010/11 and the 2009/10 seasons.

\section{Exposure to dry spells at the study sites}

In this section we assess the extent of exposure to dry spells among the sampled households and compare exposure across districts and recent years. The 2012 survey asked respondents whether or not they had experienced dry spells during the last three years (Table 1). There is obviously a subjective element in assessment of dry spell exposure. The survey did not force a special definition of the term onto the respondents but simply asked them about their own perceptions.

Table 1 shows that $74 \%$ of the sampled households were exposed to a dry spell in the 2011/12 season compared to only $18 \%$ and $9 \%$ in the previous two years. The aggregate measure indicates that, on average, $80 \%$ were exposed to a dry spell at least once during the last three years. Kasungu district appears to have had lower exposure to dry spells in recent years, as only $26 \%$ perceived that they had been exposed to a dry spell in the 2011/12 season and only $40 \%$ perceived that they had been exposed to such an event at least once in the last three years. By contrast, survey results indicated relatively high exposure to dry spells in Chiradzulu and Thyolo districts: all of the sampled households in these districts reported a dry spell at least once in the last three years. Another way to measure dry spell exposure with the survey data is with information on maize replanting. Table 1 provides district-level information for 2011/12 on the percent of sampled households that replanted after experiencing a dry spell. As indicated by the table, the dry spell caused many households $(43 \%)$ to replant maize due to crop failure, with the bulk of replanting occurring in December 2011. There is some agreement between measures of drought exposure reported in Table 1. Specifically, by both measures Kasungu district households were least exposed to dry spells, while Thyolo district households were most exposed. In a later section of the paper, we report daily rainfall data in order to compute monthly rainfall for December 2011, and January and February 2012 as an alternative way to capture the 2011/12 drought. $^{2}$ In addition, the daily rainfall data were used to estimate the length of the longest dry spell in the early rainy season (December) and mid rainy season (February). These data were available from one weather station per district.

\footnotetext{
${ }^{2}$ We used rainfall data from the following weather stations: Bvumbwe (Thyolo), Chiradzulu (Chiradzulu), Chingale (Zomba), Ntaja (Machinga), Chitedze (Lilongwe), and Kasungu (Kasumgu).
}

Table 1 Drought exposure of sampled households in the last three years, by district

\begin{tabular}{llllll}
\hline District & \multicolumn{2}{l}{ Percent reporting drought, by year } & $\begin{array}{l}\text { Percent that } \\
\text { replanted in }\end{array}$ \\
\cline { 2 - 5 } & $\begin{array}{l}\text { Drought at } \\
\text { least once } \\
\text { last 3 years }\end{array}$ & $\begin{array}{l}\text { Drought } \\
\text { in }\end{array}$ & $\begin{array}{l}\text { Drought } \\
\text { in }\end{array}$ & $\begin{array}{l}\text { Drought } \\
\text { in }\end{array}$ & $2011 / 12$ \\
& 100 & 98 & 24 & 11 & 62 \\
\hline Thyolo & 97 & 95 & 13 & 4 & 61 \\
Zomba & $9710 / 11$ & $2009 / 10$ & \\
Chiradzulu & 100 & 100 & 58 & 18 & 33 \\
Machinga & 85 & 81 & 23 & 11 & 49 \\
Kasungu & 40 & 26 & 10 & 6 & 16 \\
Lilongwe & 81 & 73 & 7 & 12 & 40 \\
Total & 80 & 74 & 18 & 9 & 43 \\
\hline
\end{tabular}

Source: Own survey data

\section{Assessing farmer uptake and demand for DT maize}

\section{Maize variety use and preferences}

In the 2011/12 agricultural season, 173 of the 351 sampled households received hybrid maize seed through the Malawi Farm Input Subsidy Program (FISP), 15 households received open pollinated (OPV) maize seed, and 34 households received legume seed. FISP, which has been implemented since $2005 / 06$, targets approximately $50 \%$ of farmers in the country to receive subsidized fertilizer for maize production, with additional vouchers for tobacco fertilizers and improved maize seed (Lunduka et al., 2013). Table 2 reports the most common maize varieties that households said they received through the subsidy program during the last three production years, distinguishing between DT and other improved maize varieties. The data suggest the FISP has played an important role in diffusing DT maize to Malawian farmers, especially in 2009/10. Between 69 and $82 \%$ of sampled farmers who received a coupon for maize seed reported that they redeemed their coupon for a DT maize variety. It is not possible to state that this distribution represents the demand for maize varieties, as supply side factors, related to what was available in the depots for distribution with the input subsidy coupons, may be more important for what households received than their own preferences.

Table 3 gives an overview of preferred maize varieties that households stated they would use if they had good access to fertilizers and if they did not have access to fertilizer, again distinguished by DT and non-DT improved maize. The data indicate high farmer demand for the DT maize varieties, particularly for SC403, and this is the case with both good and poor fertilizer access. The popularity of SC719 is impressive given the variety is rather new, released in 2008, but farmers 
Table 2 Maize varieties received as a percent of those receiving free maize seed under the FISP, by year

\begin{tabular}{llcll}
\hline Maize variety & $\begin{array}{l}\text { Hybrid } \\
\text { or OPV }\end{array}$ & $\begin{array}{c}2011 / \\
12, \%\end{array}$ & $\begin{array}{l}2010 / \\
11, \%\end{array}$ & $\begin{array}{l}2009 / \\
10, \%\end{array}$ \\
\hline $\begin{array}{l}\text { Received improved } \\
\quad \text { maize seed }\end{array}$ & & 50.7 & 54.1 & 51.9 \\
DT improved maize varieties & & 68.9 & 70.1 & 81.9 \\
SC403 - Kanyani & Hybrid & 34.4 & 39.0 & 42.3 \\
SC627 - Mkango & Hybrid & 25.0 & 23.7 & 24.7 \\
SC719 - Njovu & Hybrid & 2.2 & 0.5 & 2.2 \\
ZM523 - Demeta (OPV) & OPV & 6.7 & 5.3 & 7.7 \\
ZM623 & OPV & 0.6 & 1.6 & 5.0 \\
Other (not DT) improved & & 30.3 & 29.0 & 18.3 \\
$\quad$ maize varieties & & & & \\
Decap & Hybrid & 0.6 & 1.1 & 0 \\
DK8033 & Hybrid & 7.2 & 9.5 & 8.8 \\
DK8053 & Hybrid & 13.9 & 5.3 & 3.3 \\
DK8067 & Hybrid & 0.6 & 0 & 0 \\
DK8071 & Hybrid & 0.6 & 0 & 0 \\
DK9089 & Hybrid & 0.6 & 0 & 0 \\
MH18 & Hybrid & 2.2 & 4.2 & 0.6 \\
MH19 & Hybrid & 0.6 & 3.2 & 0.6 \\
MH41 & Hybrid & 0.6 & 0.5 & 0 \\
Pannar 413 & Hybrid & 2.8 & 0.5 & 4.4 \\
SC407 & Hybrid & 0.6 & 4.7 & 0.6 \\
\hline & & & & \\
\hline
\end{tabular}

Source: Own survey data

do not prefer the variety without good fertilizer access. To questions about unmet demands for improved maize seed, farmer responses showed that the most commonly grown varieties are also the ones that most often people have failed to obtain, $30 \%$ stated that they failed to obtain the most preferred variety in 2012 (Table 9 in Appendix). Supply constraints therefore appear to limit adoption of the most popular varieties, although the severity of this constraint appears to have reduced in recent years: $81 \%$ of surveyed farmers stated that availability of improved maize varieties has improved over the last three years.

Respondents were also asked why they preferred some varieties over others. Farmers with good access to fertilizer expressed a strong preference for high yielding maize varieties, while those with poor fertilizer access most commonly mentioned a preference for varieties having reasonable yields without fertilizer application. Early maturity was also a desirable trait, and the most popular variety, SC403, is a very early maturing variety. But other popular varieties, SC627 and SC719, are medium and long duration varieties, respectively. Among the sampled households, fewer than $3 \%$ of respondents expressed a preference for drought tolerance. This might reflect a misunderstanding of what drought tolerance is and a misconception that drought tolerant varieties have lower yields than other improved maize varieties.

\section{Estimation strategy}

We outline below the estimation strategy to assess factors associated with DT maize uptake or adoption and their performance relative to local maize and other improved maize varieties. This requires controlling for differences in intensity of fertilizer use on the different maize varieties as well as other observable and unobservable factors that may be correlated with uptake/adoption, intensity of input use, and maize productivity.

\section{DT maize uptake/adoption}

A farmer's decision to grow DT maize is influenced by many supply and demand factors, which we represent with regression models based on the three-year panel dataset and the 2011/12 cross-sectional data. The three-year panel model is specified as follows:

$$
\begin{aligned}
D T_{i p t}= & \alpha_{0}+\alpha_{1} R_{d t}+\alpha_{2} D_{i t}+\alpha_{3} R p_{i p t}+\alpha_{4} S_{i p t}+\alpha_{5} T_{t} \\
& +\alpha_{6} P_{i p t}+\alpha_{i}+\varepsilon_{i p t}
\end{aligned}
$$

Table 3 Preferred types of maize and varieties with good access and no access to fertilizer

\begin{tabular}{lcl}
\hline Name of variety & $\begin{array}{l}\text { With good access } \\
\text { to fertilizer, \% }\end{array}$ & $\begin{array}{l}\text { Without } \\
\text { fertilizer } \\
\text { access, \% }\end{array}$ \\
\hline DT maize varieties & 74.1 & 62.4 \\
SC403 - Kanyani & 35.9 & 34.1 \\
SC627 - Mkango & 22.1 & 20.8 \\
SC719 - Njovu & 15.0 & 5.8 \\
ZM535 & 1.1 & 1.7 \\
Other improved maize varieties (OIMP) & 32.4 & 30.1 \\
DK8033 & 9.1 & 9.8 \\
DK8052 & 0.7 & \\
DK8053 & 7.6 & 5.2 \\
DK8071 & 0.7 & 0.6 \\
DK9089 & 0.4 & \\
MH18 & 8.3 & \\
MH19 & 0.4 & \\
MH41 & 1.1 & \\
Pannar 413 & 2.2 & \\
Pioneer & 1.5 & \\
SC407 & 0.4 & \\
\hline
\end{tabular}

Source: Own survey data 
In eq. 1), dependent variable $D T_{i p t}$ is a dummy variable for whether or not household $i$ grew DT maize on plot $p$ in year $t$. $R_{d t}$ is a vector of variables capturing weather conditions (annual rainfall, deviation of rainfall from normal (coefficient of variation - CV\%)) in the farm household's district $d$. $D_{i t}$ indicates the household experienced a dry spell in that specific year, according to the farmer. $R p_{i p t}$ is a binary variable indicating if the drought was so severe that the household had to replant the crop. $S_{i p t}$ is a dummy for whether the household received subsidized inputs and used them on the plot. The FISP has been a major supplier of DT and other improved maize varieties in Malawi, and the complementary Agricultural Sector-Wide Approach - Support Program (ASWAP-SP) has since 2009 disseminated information about new maize varieties through a country-wide system with lead farmers and demonstration trials. Maize seed is otherwise available through commercial providers of agricultural inputs. $T_{t}$ denotes year-specific dummies and captures the trend in DT maize adoption from 2006 to 2012. $P_{i p t}$ controls for observable farm plot characteristics such as soil type, slope, fertility status, plot size and distance to plot from home. $\alpha_{i}$ captures unobservable time-invariant characteristics of households and farms such as managerial ability and unobservable land quality. We use household random effects (RE) and fixed effects (FE) specifications to test the sensitivity of the results to these alternative specifications. The household fixed effects (HHFE) approach is the best tool we have to control for selection bias related to access to subsidized inputs.

The 2011/12 dataset includes several important variables that are not part of the three-year panel dataset, allowing for an expanded model:

$$
\begin{gathered}
D T_{i p}=\alpha_{0}^{*}+\alpha_{11}^{*} \mathrm{DTsu} b_{i}+\alpha_{12}^{*} \varepsilon\left(\mathrm{DTsu} b_{i}\right)_{i}+\alpha_{2}^{*} A S_{i} \\
+\alpha_{31}^{*} D_{i 2011}+\alpha_{32}^{*} D_{i 2010}+\alpha_{4}^{*} R p_{i p}+ \\
\alpha_{5}^{*} N S_{i}+\alpha_{6}^{*} \mathrm{crra}_{i}+\alpha_{7}^{*} P_{i p}+\alpha_{8}^{*} F_{i}+\alpha_{9}^{*} G_{i} \\
+\left(D_{v}\right)+\left(\alpha_{i}\right)+\left(R_{d t}\right)+\nu_{i p} \\
{\text { DTsu } b_{i}=} \delta_{0}+\delta_{1} N A_{i}+\delta_{2} D_{v}+\varepsilon_{i}
\end{gathered}
$$

Many of the explanatory variables in eq. 2a) are the crosssection equivalents of the explanatory variables in eq. 1), but there are several important additions. In eq. 2a), the explanatory variable for receipt of subsidized DT maize $\left(D T s u b_{i}\right)$ is potentially jointly determined with the dependent variable, i.e. $D T s u b_{i}$ may be endogenous, since the selection of DT maize beneficiaries under FISP was not random but was guided by targeting criteria and influenced by local and regional politics (Holden \& Lunduka, 2013; Lunduka et al., 2013). To avoid biased coefficient estimates due to endogeneity in the DT maize seed access under FISP, we employed a control function approach to test and control for endogeneity bias: a regression model, in which the dependent variable was $D T s u b_{i}$ and the explanatory variables are described below. Equation $2 b$ ) is the first stage for the control function approach. The residuals from estimation of $2 \mathrm{~b}$ ) are included with $D T s u b_{i}$ as explanatory variables in eq. $2 a$ ). The statistical significance of the residuals provide a test for endogeneity of the DT maize subsidy variable.

As in a two-stage instrumental variables model, the control function approach requires inclusion of at least one variable in the input subsidy equation that is not in the DT maize adoption equation. A dummy variable for households having nonagricultural business income $\left(N A_{i}\right)$ was used as an instrument. Households with non-agricultural business income may be less likely to access subsidies and therefore DT seed through FISP. We see no particular reason why having non-agricultural business should make households more or less interested in adopting DT maize. We tested the statistical validity of this by also including the instrumental variable in the adoption equation in one specification. If the instrument were insignificant in the adoption model but significant in the subsidy equation, and if the error term from the first stage model were significant in the adoption model, then endogeneity is an issue and was corrected for with the control function approach. Village fixed effects were also used to capture possible cross-village differences in the distribution of DT seeds through the subsidy program that allows for non-linear identification.

$A S i$ captures extension related variables such as whether households have been exposed to and know about the ASWAP-SP program, know a lead farmer under that program, or have been visited by an extension worker during the last year. The rainfall and rainfall variability variables do not vary within villages and were therefore dropped as we used village fixed effects. We made use of recall data for exposure to drought shocks in $2011\left(D_{i 2011}\right)$ and $2010\left(D_{i 2010}\right)$ to see whether such exposure had stimulated adoption of DT maize varieties. We also included another shock variable $\left(N S_{i}\right)$ which captures the number of shocks other than drought the household experienced over the period 2009-2012, such as deaths or serious sickness in the family. Such shocks may affect both the ability and willingness to adopt. We have also included the estimated variable crra $_{i}$ which is the relative risk aversion coefficient estimated using risk experiment data from the same households (Holden, 2014). ${ }^{3}$ If DT maize is perceived by farmers as risk-reducing, but not as high-yielding as other improved maize varieties, then risk aversion should be associated with higher adoption of DT maize. The $F_{i}$ variable is a dummy for those that failed to obtain their most preferred variety, $G_{i}$ captures gender of household head, and $D_{v}$

\footnotetext{
${ }^{3}$ Holt and Laury (2002) type of hypothetical and monetary experiments were used and a structural model with a constant relative risk aversion coefficient utility function was used combining the hypothetical and monetary experiments.
} 
represents village dummy variables. The variables in parentheses are included in alternative combinations.

\section{Maize yield impact}

We sought to evaluate the yield performance of DT maize relative to other improved maize varieties and local maize, for the drought year 2011/12. While on-station and on-farm trials suggest a sizable yield advantage, there has been no complementary research to measure DT yield performance in data from farm household surveys. Household fixed effects data from only $2011 / 12^{4}$ was used to control for unobserved household and farm characteristics in the following models as it was the performance of DT maize varieties under the drought conditions of 2011/12 that was of most interest in the present study.

To assess the yield performance of the different maize varieties in the drought year 2011/12, we specified models that control for endogeneity related to access to DT maize varieties through the subsidy program, access to subsidized fertilizer through the subsidy program, unobservable factors that can affect commercial demand for fertilizer, and unobservable household ability and farm land quality characteristics. The included error terms come from eq. $2 b$ above and from three models that are available from the authors upon request. We controlled for the unobservable household ability and farm land quality with the fixed effects extracted from the threeyear plot panel model for maize yields as explained above. ${ }^{5}$ In addition to monthly rainfall levels for the critical months of December 2011, January 2012 and February $2012\left(R_{d t}\right)^{6}$, equation 3 includes variables for the number of days of the longest dry spell that occurred in December 2011 and in February $2012\left(D S_{d t}\right){ }^{7}$ and interactions between the dry spell in February with DT and local maize (LM) dummy variables. We have not included village fixed effects in these models as these are highly correlated with the

\footnotetext{
${ }^{4}$ The three-year panel model results are available from the authors upon request. The household fixed effects represent the unobservable timeinvariant household and farm characteristics that may be correlated with land productivity and that can possibly lead to bias if not controlled for.

${ }^{5}$ The three-year panel model did not give any significant difference in yield between the maize varieties. One of the reasons may be that this model is too rigid as it requires many coefficients to be constant over time while soil characteristics and fertilizer may give different responses under varying weather conditions. For example, clay soil may conserve moisture in a dry year but be associated with waterlogging in a wet year. Separate models run for each year revealed these types of differences. These models are available from the authors upon request.

${ }^{6}$ Daily rainfall data were obtained from the nearest weather stations in each district $(d)$.

${ }^{7}$ A dry spell is defined as the number of consecutive days with less than $5 \mathrm{~mm}$ rain. The dry spell was allocated to the month where most of it takes place, thus allowing it to go into neighboring months. We were interested in early dry spells (in December) that may affect all types of maize negatively and late dry spells (in February) during silking/grain formation.
}

drought variables and the rainfall variables that also do not vary within villages.

$$
\begin{aligned}
Y_{i p}^{H a} & =\lambda_{0}+\lambda_{1} D T_{i p}+\lambda_{2} L M_{i p}+\lambda_{3} R_{d t}+\lambda_{4} D S_{d t} \\
& +\lambda_{5} D T_{i p} * D S_{d t=F e b}+\lambda_{6} L M_{i p} * D S_{d t=F e b} \\
& +\lambda_{7} P_{i p}+\left(\lambda_{8} E_{i p}+\lambda_{9} v\left(E_{i p}\right)+\lambda_{10} \alpha_{i}\right)+\xi_{i p}
\end{aligned}
$$

In model 3 it is particularly the DT maize and local maize (LM) dummy variables and their interactions with the late dry spell in 2011/12 that we are interested in, while controlling for farm plot characteristics (land quality) and other variables. We have specified models without and with the maize variety and drought interaction variables. Models were run without and with endogenous variables $\left(E_{i p}\right)$ such as source of access to DT maize as well as log-transformed subsidized and commercial fertilizer, including their error terms from separately run models to control for their endogeneity (control function approach) and unobserved household heterogeneity. ${ }^{8}$ The other variables in equation 3 are as specified in relation to eq. 2 a.

\section{Results and discussion}

\section{DT maize adoption}

The adoption model results are presented in Tables 4 and 5 . Table 4 and Appendix Table 7 show the adoption trend from 2006 to 2012, which indicates a substantial increase in the adoption of DT varieties over this time period. Results also indicate that the increase in adoption was strongly associated with FISP. The model with household fixed effects, which controls better for unobservable household and farm characteristics, reveals a more significant effect of the subsidy program on DT adoption.

Table 5 provides a more comprehensive analysis of factors associated with DT maize adoption in the 2011/12 season. As mentioned earlier, we used a control function approach to handle sample selection related to receiving DT maize through FISP, and non-agricultural business was the instrumental variable left out in the second stage regressions. The first model in Table 5 is the first stage model, the second model in Table 5 includes the instrument in the second stage to assess statistical validity. As shown, non-agricultural business income was significant at the $5 \%$ level and with a negative sign in the first model, and the instrument was not significant at standard test levels in the second model, while the error term from the first stage model was significant at the $5 \%$ level and with negative sign in two of the models and significant at $10 \%$ in one of the models. Our control function approach therefore appears to have worked. We used four different specifications of the

\footnotetext{
${ }^{8}$ This was done by including the household fixed effects extracted from the three-year panel model for maize productivity.
} 
Table 4 Linear probability models for DT maize adoption with household-farm plot panel from 2006, 2009 and 2012 (maize plots)

Village FE \& Household Household FE RE

\begin{tabular}{lll}
\hline Annual rain, mm & $0.000(0.000)$ & $0.000(0.001)$ \\
Rain deviation, CV\% & $-0.002(0.002)$ & -0.002 \\
& & $(0.008)$ \\
Drought_2012 & $-0.050(0.088)$ & $-0.025(0.087)$ \\
Replant_2012 & $-0.007(0.070)$ & $0.009(0.076)$ \\
Fertilizer subsidy, dummy & $0.038^{*}(0.022)$ & $0.056^{* *}(0.026)$ \\
Year 2009, dummy & $0.188^{* * * *(0.025)}$ & $0.199^{* * * *}$ \\
& & $(0.029)$ \\
Year 2012, dummy & $0.464^{* * * *}(0.069)$ & $0.440^{* * * *}$ \\
& & $(0.066)$ \\
Farm plot characteristics & Yes & Yes \\
Village FE & Yes & Yes \\
Household FE & No & $-0.027(0.828)$ \\
Constant & $-0.175(0.214)$ & \\
Wald chi & 342.279 & 18.146 \\
F-value & & 0.000 \\
Prob > chi2 & 0.000 & 1744 \\
Observations & 1744 & 0.239 \\
R-squared & & \\
\hline
\end{tabular}

Dependent variable is a dummy for drought tolerant maize variety grown on the plot. Land quality controls include soil type, slope, and soil fertility classes. Significance levels: *: $10 \%$, **: $5 \%, * * *: 1 \%$, ****: $0.1 \%$. Robust standard errors

second stage. The first included the instrument as a test for its statistical validity, while the second excluded the instrument. The third specification included the ASWAP-SP and extension visit variables, as well as the household fixed effects from the three-year maize productivity models as controls for unobservable farmer ability and farm land quality. The fourth specification included the average annual rainfall and rainfall deviation variables. The household fixed effects variable was only significant at the $10 \%$ level in one of the specifications and with a negative sign. This indicates that farmers who were more productive (e.g., due to unobservable ability or better land quality) were not more likely to adopt DT maize.

The dummy variable for receiving DT maize through the subsidy program was highly significant (at the $0.1 \%$ level) and with a positive sign in all model specifications. The receivers of DT maize through the subsidy program were $78 \%$ more likely to use DT maize. This is compelling evidence that the FISP was a strong driver, which encouraged DT maize adoption in the country. However, when we included a dummy variable for having accessed DT maize through the subsidy program in the previous two years, this variable was insignificant, giving reason to be cautious about interpreting the use of DT maize in 2012 as a sign of adoption. It appears that
DT maize uptake is partly a result of access to free seeds through FISP.

We wanted to explore whether the Agricultural SectorWide Support Programme (ASWAP-SP) which has expanded dissemination of improved maize varieties and conservation programs had started to make a visible impact on DT maize adoption in our study areas. Findings did not indicate a significant impact of the program on DT maize adoption in our sample, but this may reflect that the program only has been operational since 2009 and has expanded gradually to new areas. Visits by extension staff in the previous year were not significant in any of the specifications. The agricultural extension programs therefore seem not to be an important driver of DT maize adoption.

Next, we assessed whether exposure to drought shocks in previous years (2010 and 2011) affected DT adoption. Earlier drought shocks may have given farmers experience or interest in adopting DT varieties. Results showed that exposure to drought shocks in 2010 was associated with significantly (at the $5 \%$ level) higher adoption of DT maize varieties. Farmers with such exposure were 18-20\% more likely to plant DT maize. This result was robust to alternative specifications.

We also tested the effects of the 2012 drought and of this drought causing households to have to replant their maize crop. While the 2012 drought dummy had no significant effect on DT maize adoption, the replanting dummy was significant (at the $5 \%$ level) and with a positive sign. Those who had to replant their maize crop were $8-12 \%$ more likely to use DT maize. The survey asked about the source of seed in case of replanting. Subsidized seed appears not to have been available at that time. There were 211 sampled households which had replanted after the 2012 drought and they reported their seed sources as: purchased seed (52.1\%), own seed (33.2 \%), seed received as a gift from friends ( $8.1 \%$ ), recycled seed $(5.2 \%)$, and seed coupon $(1.4 \%)$. It is logical that those who were forced to replant their maize chose to grow an early maturing variety such as the DT variety SC403. In fact, SC403 was planted by $29.2 \%$ of those households that replanted, but only by $24.3 \%$ of households at the start of the $2011 / 12$ rainy season.

A measure of relative risk aversion, based on experimental data, was included in the model. If DT maize is perceived to reduce production risk, we expect that more risk averse farmers are more likely to adopt DT maize. Our results support this. The variable was significant at the $10 \%$ level and with positive sign in two of the specifications and the effect of this preference variable may have been controlled away when household fixed effects were included. A one unit change in the constant relative risk aversion coefficient was associated with a $15 \%$ increase in the adoption of DT maize. This may indicate that the awareness of DT maize as a risk-reducing technology has started to make its impact on maize variety adoption in Malawi. 
Table 5 DT maize adoption models with control function approach for access to DT maize through the subsidy program, 2012 data

\begin{tabular}{|c|c|c|c|c|c|}
\hline & 1.stage IV & CF1 & $\mathrm{CF} 2$ & $\mathrm{CF} 3$ & CF4 \\
\hline Instrument: Nonagricultural business & $-0.083 * *(0.038)$ & $0.045(0.035)$ & & & \\
\hline $\begin{array}{l}\text { Received DT maize through subsidy } \\
\text { program (DTsub) }\end{array}$ & & $0.795 * * * *(0.090)$ & $0.785 * * * *(0.087)$ & $0.759 * * * *(0.095)$ & $0.759 * * * *(0.082)$ \\
\hline $\begin{array}{l}\text { Error term for received DT maize through } \\
\text { subsidy program model }\end{array}$ & & $-0.162 * *(0.069)$ & $-0.154 * *(0.066)$ & $-0.135^{*}(0.077)$ & $-0.150 * *(0.062)$ \\
\hline \multicolumn{6}{|l|}{ Baseline: Know ASWAP-SP very well } \\
\hline Familiar with ASWAP-SP, but not well & & & & $-0.057(0.062)$ & $-0.015(0.058)$ \\
\hline Unfamiliar with ASWAP-SP & & & & $-0.081(0.059)$ & $-0.058(0.056)$ \\
\hline Seen ASWAP-SP demonstration plots & & & & $0.009(0.060)$ & $0.024(0.052)$ \\
\hline Know ASWAP-SP lead farmer & & & & $-0.05(0.070)$ & $-0.036(0.061)$ \\
\hline Visited by extension staff last year & & & & $0.007(0.020)$ & $0.01(0.019)$ \\
\hline Drought_2012, dummy & & $-0.069(0.063)$ & $-0.074(0.063)$ & $-0.111(0.076)$ & $-0.083(0.069)$ \\
\hline Drought_2011, dummy & & $0.022(0.047)$ & $0.019(0.046)$ & $0.013(0.049)$ & $0.008(0.049)$ \\
\hline Drought_2010, dummy & & $0.182 * *(0.085)$ & $0.182 * *(0.083)$ & $0.204 * *(0.084)$ & $0.183 * *(0.080)$ \\
\hline Replant_2012 after dry spell, dummy & & $0.078 * *(0.034)$ & $0.083 * *(0.034)$ & $0.102 * * *(0.036)$ & $0.121 * * * *(0.035)$ \\
\hline Number of shocks, 2009-2012 & & $0.029(0.021)$ & $0.03(0.021)$ & $0.021(0.024)$ & $0.027(0.021)$ \\
\hline Relative risk aversion coefficient & & $0.154 *(0.089)$ & $0.148 *(0.088)$ & $0.136(0.092)$ & $0.038(0.076)$ \\
\hline Failed to get preferred maize variety, dummy & & $-0.023(0.038)$ & $-0.019(0.038)$ & $-0.001(0.043)$ & $-0.024(0.040)$ \\
\hline Sex of household head = female, dummy & & $-0.053(0.036)$ & $-0.056(0.037)$ & $-0.051(0.039)$ & $-0.055(0.036)$ \\
\hline Unobservables control (HHFE) & & & & $-0.118^{*}(0.070)$ & $-0.138(0.094)$ \\
\hline Average annual rainfall & & & & & $-0.002(0.001)$ \\
\hline Rainfall deviation (CV\%) & & & & & $0.012(0.010)$ \\
\hline Farm plot characteristics & Yes & Yes & Yes & Yes & Yes \\
\hline Village FE & Yes & Yes & Yes & Yes & No \\
\hline Constant & $0.175^{* *}(0.084)$ & $-0.278(0.197)$ & $-0.247(0.189)$ & $-0.279(0.211)$ & $1.683(1.122)$ \\
\hline Wald chi & 138.367 & 1038.092 & 1088.975 & 1138.398 & 744.937 \\
\hline Prob $>$ chi2 & 0.000 & 0.000 & 0.000 & 0.000 & 0.000 \\
\hline Rho & 0.000 & 0.639 & 0.639 & 0.650 & 0.651 \\
\hline Observations & 582 & 489 & 489 & 461 & 461 \\
\hline
\end{tabular}

Dependent variable: Dummy for use of DT maize at plot level. Linear probability models with household random effects. Selection bias in relation to obtaining DT maize through the subsidy program was tested for with a Control Function approach using visit by extension staff and having nonagricultural business as instruments. The robustness of the results was tested by alternatively including instruments in second stage to test their statistical validity and by control for unobservables as follows: Control for unobservable household and farm characteristics was included as the household fixed effects extracted from a three-year panel model for maize productivity (Unobservables control (HHFE)). DT varieties include SC403, SC627, SC719, ZM521,ZM523 and ZM621. Significance levels: *: $10 \%$, **: $5 \%, * * *: 1 \%, * * * *: 0.1 \%$. Standard errors were bootstrapped by resampling households, with 400 replications

\section{DT maize yield impact}

Figure 1 gives an overview of the yield distributions for the three types of maize in 2011/12, while Fig. 2 shows the yield distributions for DT and local maize for households that stated they were affected by the 2011/12 dry spell and those that stated they were not affected. From Fig. 1 it appears that DT maize performed better than local maize, but not better than other improved varieties. Figure 2 indicates that DT maize performed better than local maize under both drought and non-drought conditions. The average yield in $\mathrm{kg} / \mathrm{ha}$ was 1275 for DT maize, 1050 for local maize and 1615 for other improved varieties. The regression models can provide a stronger basis for assessing the significance of these differences and their causes. Table 6 presents the results for the test of the DT maize varieties versus local maize and other improved maize varieties using the maize yield data from 2012 when a severe dry spell occurred early in the rainy season in much of the country. We assessed the performance of the different maize varieties in areas more or less seriously affected by the dry spell. We included monthly rainfall for the three most critical months, December, January and February in all Table 6 models. The last three models in the table added variables for the length of the longest dry spells in the early rainy season (December) and mid rainy season during silking/grain formation (February). Robustness checks were included by running models without and with the interaction of maize variety and dry spell in February, the time 
Fig. 1 Maize yield distributions by maize type in 2011/12 season

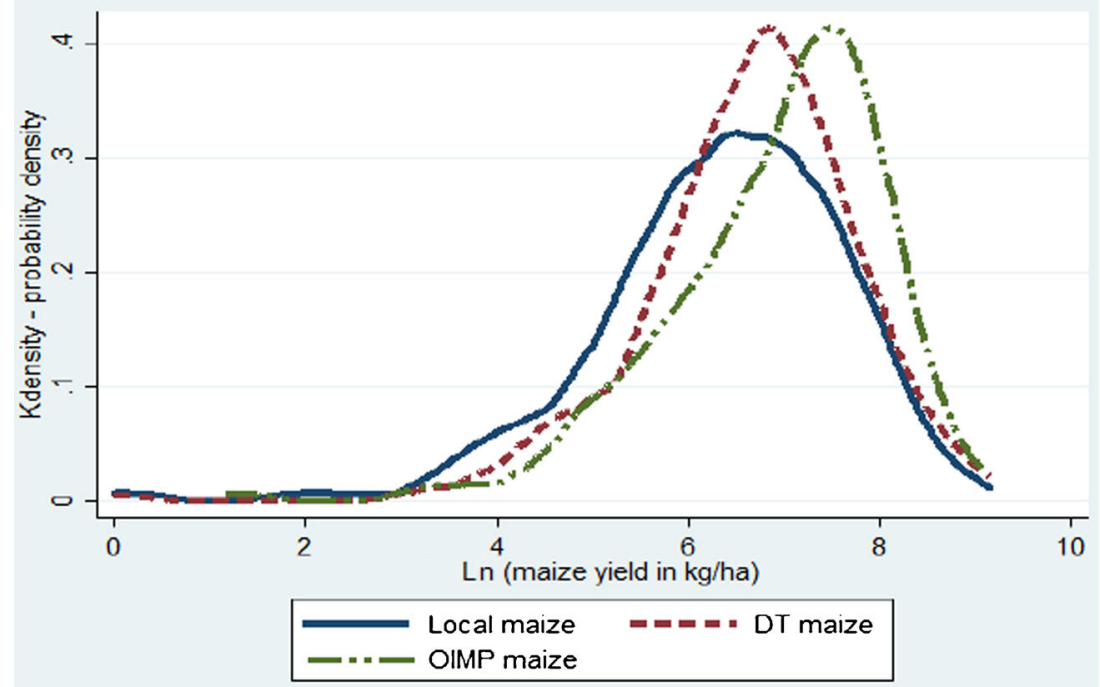

when we would expect that DT out-performs other varieties if drought occurs. We ran models without (models Y1 and Y3) and with (models Y2, Y4 and Y5) a set of endogenous variables and controls for their endogeneity, using a control function approach. The control function approach involved including three error terms; one for access to DT maize through the subsidy program, the second for access to subsidized fertilizer, and the third for access to commercial fertilizer.

The first two models in Table 6 indicate that local maize had significantly lower yield than DT maize and other improved maize varieties, but DT maize did not give yields that were significantly better than the other improved maize varieties. Of the monthly rainfall variables only the December rain was significant and positively associated with maize yields. This is consistent with our expectations regarding the severe early rainy season drought. With inclusion of endogenous variables and additional controls (model Y2), this main result did not change except the coefficients on local maize and December rainfall were slightly reduced and the level of significance was reduced from $1 \%$ level to $5 \%$ level for both variables.

With inclusion of the dry spell variables in model Y3 the monthly rainfall in January and February became significant while the dry spell variables were insignificant. The January rainfall variable has a negative sign indicating excess rain in this period, while the sign is positive and significant for the February rainfall but its coefficient is much smaller than that for the December rainfall, indicating a less severe drought in February. With the addition of endogenous variables and controls for endogeneity in model Y4, the dry spell in December
Fig. 2 Maize yield distributions for DT maize and local maize with and without drought

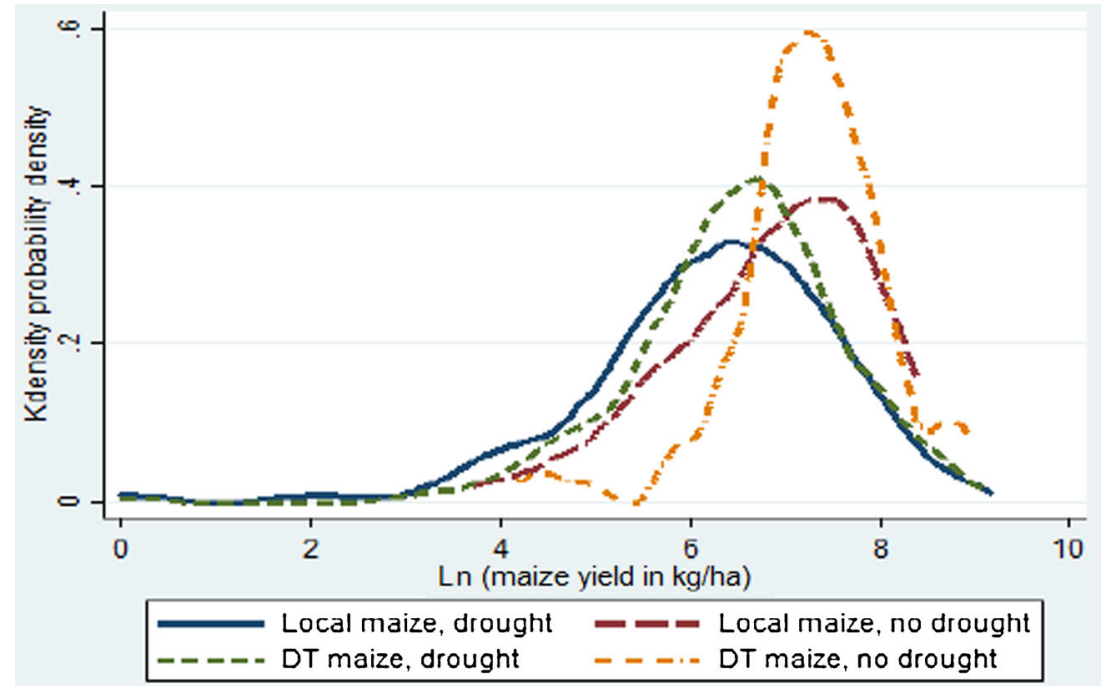


Table 6 Cobb-Douglas Maize yield models 2012 without and with dry spell and late dry spell*variety interactions and control function approach to test and control for endogeneity in subsidy access, seed access and fertilizer use

\begin{tabular}{|c|c|c|c|c|c|}
\hline & Y1 & Y2 & Y3 & Y4 & Y5 \\
\hline DT maize varieties & $0.078(0.110)$ & $0.107(0.123)$ & $0.121(0.111)$ & $0.120(0.123)$ & $0.448 * *(0.226)$ \\
\hline Local maize & $-0.248 * * *(0.094)$ & $-0.221 * *(0.111)$ & $-0.215 * *(0.095)$ & $-0.163(0.111)$ & $-0.109(0.329)$ \\
\hline Rainfall December 2011, mm & $0.021 * * *(0.008)$ & $0.015 * *(0.006)$ & $0.051 * * * *(0.014)$ & $0.044 * * * *(0.011)$ & $0.045 * * * *(0.012)$ \\
\hline Rainfall January 2012, mm & $-0.000(0.001)$ & $-0.000(0.001)$ & $-0.005 * *(0.002)$ & $-0.004 * * *(0.002)$ & $-0.004 * * *(0.002)$ \\
\hline Rainfall February 2012, mm & $0.005(0.003)$ & $0.002(0.002)$ & $0.014 * * *(0.005)$ & $0.010 * * *(0.003)$ & $0.010 * * *(0.003)$ \\
\hline Longest dry spell December 2011, days & & & $-0.014(0.014)$ & $-0.022 * *(0.010)$ & $-0.026^{* *}(0.011)$ \\
\hline Longest dry spell February 2012, days & & & $0.049(0.032)$ & $0.033 *(0.019)$ & $0.039 *(0.021)$ \\
\hline DT maize*Dry spell February & & & & & $-0.035(0.022)$ \\
\hline Local maize*Dry spell February & & & & & $-0.005(0.026)$ \\
\hline Farm plot characteristics & Yes & Yes & Yes & Yes & Yes \\
\hline Endogenous variables and controls & No & Yes & No & Yes & Yes \\
\hline Wald chi & 224.248 & 572.258 & 232.726 & 607.688 & 616.446 \\
\hline Prob > chi2 & 0.000 & 0.000 & 0.000 & 0.000 & 0.000 \\
\hline Rho & 0.352 & 0.195 & 0.342 & 0.180 & 0.171 \\
\hline Observations & 566 & 561 & 566 & 561 & 561 \\
\hline
\end{tabular}

Dependent variable: $\mathrm{Log}$ of maize yield in $\mathrm{kg} / \mathrm{ha}$. Endogenous variables and controls: Log of subsidized fertilizer and commercial fertilizer used on the plot, seed access through the subsidy program, household fixed effects from 3-year panel models (models Y2, Y4 and Y5), error terms from maize access through subsidy program, access to subsidized fertilizer, and demand for commercial fertilizer. Significance levels: *: $10 \%$, **: $5 \%$, ***: $1 \%$, ****: $0.1 \%$. Standard errors in parentheses are robust in models Y1 and Y3 and bootstrapped by resampling households, with 400 replications in models Y2, Y4 and Y5

and February variables also become significant at 5 and $10 \%$ levels, and the December dry spell variable has the expected negative sign. The February dry spell variable, however, has a positive sign, and rainfall in February also has a positive and significant sign. One possible explanation is that the dry spell in February was beneficial, as it helped to dry up the soil after the excess January rains.

The variety and February drought interaction variables were included in model Y5, but they were insignificant while the dummy for DT maize became significant at $5 \%$ level. This shows that the February dry spell was not severe enough for DT maize yields to benefit much from the DT maize traits.

\section{Conclusions}

Maize is the main staple food crop for rural smallholder households that dominate Malawi's countryside. The crop is highly susceptible to drought, and climate variability and climate change threaten household and national food security. Several drought tolerant (DT) maize varieties have recently been developed and disseminated to farmers in Malawi and other SSA countries, and there is urgent need to evaluate the merits of these promising technologies for drought risk mitigation. The present paper is among the first to measure the degree of adoption and evaluate, under farmer conditions, the yield advantage of DT maize technologies under moderate drought conditions. The study employed cross-sectional and panel data for 350 farm households residing in six districts of Central and Southern Malawi, with focus on the 2011/12 production season in which widespread drought occurred in Malawi.

Our analysis of DT maize adoption revealed that adoption of DT maize has expanded substantially from 2006 to 2012 . The main driver of this adoption was the subsidy program (FISP), which has distributed free seeds in addition to highly subsidized fertilizer to smallholder households since 2005/06. However, we also found that lack of access to commercial seeds constrained the adoption of DT maize varieties. About $30 \%$ of the households stated that they were unable to obtain the most preferred maize variety in the 2011/12 season. The most popular varieties were the most commonly grown DT varieties, suggesting that there is room for further expansion of such varieties. Exposure to an earlier drought (in 2009/10) was associated with significantly higher demand for DT maize in 2011/12, suggesting that the farmer's decision to start cultivating DT maize was partly in response to climatic variability. Research in Tanzania and Nigeria also found farmers switching to crop varieties less sensitive to climatic stress as a strategy to adapt to climate variability and change (Westengen \& Brysting, 2014; Tambo \& Abdoulaye, 2013). 
Another main finding of our study is that more risk averse households had a significantly higher demand for DT maize. Jain et al. (2015) similarly found for Gujarat, India that farmer risk aversion was associated with increased adaptation to climate variability.

As far as yield performance is concerned, improved maize varieties performed significantly better than local maize during the 2011/12 drought year. However, DT maize did not perform significantly better than other improved maize varieties used in Malawi, which is in contradiction to results from on-station and on-farm trials (e.g., Magorokosho et al., 2010; Setimela et al., 2012). Findings suggest that, for farmers who moved from cultivating local to DT maize, this change was adaptive, that is it conferred significant benefit in maize yield. This finding agrees with other research in SSA indicating a consistent yield advantage of improved maize varieties over local maize varieties at different levels of fertilizer use and various soil fertility and rainfall conditions (Smale \& Jayne, 2003). But the change from cultivation of non-DT improved maize to DT improved maize did not appear to offer any benefit in maize yield.

The finding of no yield advantage of DT improved maize over non-DT improved maize may appear surprising, given the results of on-station and on-farm trials. This is plausibly explained by the fact that the severe dry spell in the 2011/12 season in Malawi occurred early in the rainy season and DT maize does not offer any advantages over other maize varieties in the case of such early droughts. It is for droughts occurring later, during the silking/grain filling stage that DT maize performs better than other maize varieties. While some areas experienced a dry spell also in February 2012 this drought was not severe enough for DT maize to out-perform other varieties. While further research is needed, our preliminary results suggest that DT maize only offers partial protection against drought that depends on the timing of the drought.

For now, continuation of the Malawi FISP will ensure continued cultivation of the DT maize varieties, which have commonly been featured under the input subsidy program. FISP has greatly assisted the DTMA project in its efforts to get DT seed to Malawi farmers, but this situation is not replicated in the other 12 African countries where DT maize seed has been disseminated. A recent study found that $61 \%$ of sampled maize plots in Malawi were planted to DT maize varieties, whereas for the other five study countries corresponding figures ranged from $9 \%$ to $26 \%$ (Fisher et al., 2015). The same study revealed barriers to adoption of DT maize, including unavailability of improved seed, inadequate information, lack of resources, high seed prices, and farmers' perceptions of variety attributes. Outside Malawi, therefore, specific combinations of supply-side (e.g., ensuring seed availability in local markets) and demand-side (e.g., ensuring farmer awareness of DT seed) solutions to low adoption of DT maize seed need to be sought. First, the supply of seed to local markets must be adequate to allow farmers to buy, experiment with, and learn about DT maize. Second, to make seed more accessible to farmers with limited cash or credit (another major barrier), seed companies and agro-dealers should consider selling DT maize seed in affordable micro-packs ( 1 or $2 \mathrm{~kg}$ ) (Holden \& Lunduka, 2014). In addition, enhanced adoption depends on enhanced awareness, which could be achieved through demonstration plots, field days, and distribution of print and electronic promotional materials.

Finally, it is important to recognize that while our study focused on DT maize for adaptation to climate variability and change, there are many proven agricultural adaptations for promoting household food security in Malawi and elsewhere, for example cultivation of drought tolerant crops such as cassava and pigeon pea. However, the early 2015 serious flood in the country illustrates the limitations of any crop or crop variety as protection against all extreme weather conditions.

Acknowledgments Funding for this research was received from Norwegian Agency for Development Cooperation (NORAD) under NORAD's Programme for Master Studies (NOMA) for the 2006 and 2009 household surveys, from the Norwegian University of Life Sciences, and the International Maize and Wheat Improvement Center (CIMMYT) projects "Measuring the poverty and food security impacts of improved maize in Africa: A combined econometric and micro economy-wide modelling approach" (under the Standing Panel on Impact Assessment (SPIA)) and "Identifying socioeconomic constraints to and incentives for faster technology adoption: Pathways to sustainable intensification in Easter and Southern Africa (Adoption Pathways)." We acknowledge valuable contributions by Rodney Lunduka in the 2006 and 2009 surveys and Julius Mangosoni during the 2012 survey and institutional collaboration with Bunda College of Agriculture/Lilongwe University of Agriculture and Natural Resources during fieldwork. We are not aware of any conflicts of interest related to this research. All remaining errors are the responsibility of the authors.

\section{Appendix. Overview of variables in 3-year panel and 2012 extended data.}

Table 7 Overview of adoption/use of maize types

\begin{tabular}{|c|c|c|c|c|c|}
\hline Year & & Local maize & DT maize & $\mathrm{OIMP}^{1)}$ maize & Total \\
\hline \multirow[t]{2}{*}{2006} & No of plots & 295 & 20 & 525 & 840 \\
\hline & $\%$ of plots & 35.12 & 2.38 & 62.50 & 100.00 \\
\hline \multirow[t]{2}{*}{2009} & No of plots & 273 & 130 & 225 & 628 \\
\hline & $\%$ of plots & 43.47 & 20.70 & 35.83 & 100.00 \\
\hline \multirow[t]{2}{*}{2012} & No of plots & 143 & 249 & 163 & 555 \\
\hline & $\%$ of plots & 25.77 & 44.86 & 29.37 & 100.00 \\
\hline \multirow[t]{2}{*}{ Total } & No of plots & 711 & 399 & 913 & 2023 \\
\hline & $\%$ of plots & 35.15 & 19.72 & 45.13 & 100.00 \\
\hline
\end{tabular}

Source: Own survey data.1) OIMP: Other improved maize varieties 
Table 8 List of variables for 3 year panel

\begin{tabular}{lrrrrl}
\hline Variable & Obs & Mean & Std. Dev. & Min & Max \\
\hline Log(Maize yield in kg/ha + 1) & 1719 & 6.000 & 2.371 & 0 & 9.210 \\
Soil type, 1 = sandy, 2 = loam, 3 = clay & 1978 & 1.932 & 0.692 & 1 & 3 \\
Slope, 1 = flat, 2 = slight, 3 = steep & 1970 & 1.453 & 0.610 & 1 & 3 \\
Plot fertility, 1 = high, 2 = medium, 3 = low & 1994 & 2.071 & 0.633 & 1 & 3 \\
Annual rain, mm & 2013 & 911.766 & 248.720 & 334.3 & 1359 \\
Rain deviation, CV\% & 2013 & -0.263 & 21.383 & -57.999 & 33.91 \\
Fertilizer subsidy access, dummy & 1924 & 0.549 & 0.498 & 0 & 1 \\
Log(Fertilizer use intensity in kg/ha + 1) & 1719 & 3.602 & 2.378 & 0 & 6.686 \\
DT maize, dummy & 2023 & 0.197 & 0.398 & 0 & 1 \\
Local maize (LM), dummy & 2023 & 0.402 & 0.490 & 0 & 1 \\
Drought_2012, dummy & 2023 & 0.220 & 0.415 & 0 & 1 \\
Replant_2012, dummy & 2023 & 0.106 & 0.308 & 0 & 1 \\
DT maize*Drought_2012 & 2023 & 0.098 & 0.298 & 0 & 1 \\
LM maize*Drought_2012 & 2023 & 0.105 & 0.307 & 0 & 1 \\
Log(Plot size in ha) & 1719 & -1.341 & 0.942 & -5.988 & 4.285 \\
\hline
\end{tabular}

Source: Own survey data

Table 9 List of 2012 variables

\begin{tabular}{|c|c|c|c|c|c|}
\hline Variable & Obs & Mean & Std. Dev. & Min & Max \\
\hline DT maize, yield in $\mathrm{kg} / \mathrm{ha}$ & 269 & 1275.2 & 85.2 & 0.0 & 9595.1 \\
\hline Local maize, yield in $\mathrm{kg} / \mathrm{ha}$ & 259 & 1049.8 & 76.2 & 0.0 & 9595.1 \\
\hline Grow DT maize on plot & 591 & 0.455 & 0.498 & 0 & 1 \\
\hline Received DT through subsidy program & 591 & 0.387 & 0.488 & 0 & 1 \\
\hline Plot size in ha & 593 & 0.359 & 0.442 & 0.01 & 8.15 \\
\hline Plot distance, meters & 584 & 937 & 1573 & 0 & 16,000 \\
\hline Subsidized fertilizer access, dummy & 593 & 0.408 & 0.492 & 0 & 1 \\
\hline Failed to get preferred maize variety & 593 & 0.302 & 0.459 & 0 & 1 \\
\hline Monthly rain December 2011, mm & 593 & 102.6 & 20.4 & 75.7 & 134.7 \\
\hline Monthly rain January 2012, mm & 593 & 328.7 & 118.2 & 176.3 & 507.5 \\
\hline Monthly rain February 2012, mm & 593 & 129.2 & 44.3 & 57.1 & 204.7 \\
\hline Dry spell length December, days & 593 & 19.4 & 8.0 & 12.0 & 32.0 \\
\hline Dry spell length February, days & 593 & 10.0 & 4.8 & 4.0 & 19.0 \\
\hline Drought_2011, dummy & 511 & 0.217 & 0.413 & 0 & 1 \\
\hline Drought_2010, dummy & 511 & 0.078 & 0.269 & 0 & 1 \\
\hline Drought_2012, dummy & 593 & 0.803 & 0.398 & 0 & 1 \\
\hline Replant_2012, dummy & 593 & 0.381 & 0.486 & 0 & 1 \\
\hline Sex of household head = female, dummy & 587 & 0.588 & 0.493 & 0 & 1 \\
\hline Relative risk aversion coefficient & 586 & 1.740 & 0.282 & 0.99 & 2.21 \\
\hline Number of shocks 2009-12 & 591 & 1.645 & 0.867 & 0 & 4 \\
\hline Unobservables household-farm (HHFE) & 737 & 0.049 & 0.751 & -4.57 & 4.43 \\
\hline Knowledge of ASWAP-SP: 1 = Very well & 162 & 0.316 & & & \\
\hline Knowledge of ASWAP-SP: 2 = Yes, but not very well & 104 & 0.203 & & & \\
\hline Knowledge of ASWAP-SP: $3=$ No knowledge & 247 & 0.482 & & & \\
\hline Seen ASWAP-SP demonstration trials & 593 & 0.359 & 0.480 & 0 & 1 \\
\hline Know lead farmer under ASWAP-SP & 593 & 0.277 & 0.448 & 0 & 1 \\
\hline Has been visited by extension staff last year & 593 & 0.071 & 0.257 & 0 & 1 \\
\hline Soil type $(1=$ sand, $2=$ loam, $3=$ clay $)$ & 593 & 2.029 & 0.658 & 1 & 3 \\
\hline Slope $(1=$ flat, $2=$ slight, $3=$ steep $)$ & 591 & 1.457 & 0.633 & 1 & 3 \\
\hline Plot fertility $(1=$ very fertile, $2=$ average, $3=$ infertile $)$ & 590 & 1.920 & 0.520 & 1 & 3 \\
\hline
\end{tabular}


Table 9 (continued)

\begin{tabular}{lllll}
\hline Variable & Obs & Mean & Std. Dev. & Min \\
\hline Weed infestation (1 = high, 2 = medium, 3 = low) & 591 & 1.782 & 0.652 & 1 \\
Tropical livestock units & 591 & 0.561 & 1.740 & 0 \\
Non-agricultural business, dummy & 582 & 0.442 & 0.497 & 0 \\
DT maize error term (used in CF models) & 582 & -0.165 & 0.405 & -0.967 \\
\hline
\end{tabular}

Source: Own survey data

Open Access This article is distributed under the terms of the Creative Commons Attribution 4.0 International License (http:// creativecommons.org/licenses/by/4.0/), which permits unrestricted use, distribution, and reproduction in any medium, provided you give appropriate credit to the original author(s) and the source, provide a link to the Creative Commons license, and indicate if changes were made.

\section{References}

Alene, A. D., Menkir, A., Ajala, S. O., Badu-Apraku, B., Olanrewaju, A. S., Manyong, V. M., \& Ndiaye, A. (2009). The economic and poverty impacts of maize research in west and central Africa. Agricultural Economics, 40, 535-550.

Burke, M., \& Lobell, D. (2010). Food security and adaptation to climate change: What do we know? In Lobell D. \& Burke, M (eds.) Climate Change and Food Security, http://link.springer.com/book/10.1007\% 2F978-90-481-2953-9.

CIMMYT (2013). The drought tolerant maize for Africa project. DTMA Brief, September. International Maize and Wheat Improvement Center. http://dtma.cimmyt.org/index.php/about/background.

Deressa, T. T., Hassan, R. M., Ringler, C., Alemu, T., \& Yusuf, M. (2009). Determinants of farmers' choice of adaptation methods to climate change in the Nile basin of Ethiopia. Global Environmental Change, $19(2), 248-255$.

Dillon, A., Mueller, V., \& Salau, S. (2011). Migratory responses to agricultural risk in northern Nigeria. American Journal of Agricultural Economics, 93(4), 1048-1061.

Fisher, M., Chaudhury, M., \& McCusker, B. (2010). Do forests help rural households adapt to climate variability? Evidence from southern Malawi. World Development, 38(9), 1241-1250.

Fisher, M., Abate, T., Lunduka, R. W., Asnake, W., Alemayehu, Y., \& Madulu, R. B. (2015). Drought tolerant maize for farmer adaptation to drought in sub-Saharan Africa: determinants of adoption in eastern and southern Africa. Climatic Change, 1-17.

Holden, S. T. (2014). Risky choices of poor people: comparing risk preference elicitation approaches in field experiments. CLTS Working Paper No. 10/2014. Centre for Land Tenure Studies, Norwegian University of Life Sciences, Ås, Norway.

Holden, S. T., \& Lunduka, R. (2012). Do fertilizer subsidies crowd out organic manures? The case of Malawi. Agricultural Economics, 43, 301-312.

Holden, S. T., \& Lunduka, R. (2013). Who benefit from Malawi's farm input subsidy program? Forum for Development Studies, 40, 1-25.

Holden, S. T., \& Lunduka, R. (2014). Input subsidies, cash constraints and timing of input supply. American Journal of Agricultural Economics, 96(1), 290-307.

Holt, C. A., \& Laury, S. K. (2002). Risk aversion and incentive effects. American Economic Review, 92(5), 1644-1655.

Intergovernmental Panel on Climate Change (IPCC) (2014). Climate Change 2014: Impacts, adaptation, and vulnerability. Part B: Regional Aspects.
Contribution of Working Group II to the Fifth Assessment Report of the Intergovernmental Panel on Climate Change [Barros, V.R., Field, C.B., Dokken, D.J., Mastrandrea, M.D., Mach, K.J., Bilir, T.E., Chatterjee, M., Ebi, K.L., Estrada, Y.O., Genova, R.C., Girma, B., Kissel, E.S., Levy, A.N., MacCracken, S., Mastrandrea, P.R., \& White L.L., (eds.)]. Cambridge, United Kingdom and New York, NY, USA: Cambridge University Press.

Jain, M., Naeem, S., Orlove, B., Modi, V., \& DeFries, R. S. (2015). Understanding the causes and consequences of different decisionmaking in adaptation research: adapting to a delayed monsoon onset in Gujarat, India. Global Environmental Change, 31, 98-109.

Kijima, Y., Otsuka, K., \& Sserunkuuma, D. (2011). An inquiry into constraints on a green revolution in sub-Saharan Africa: the case of NERICA rice in Uganda. World Development, 39(1), 77-86.

Kinsey, B., Burger, K., \& Gunning, J. W. (1998). Coping with drought in Zimbabwe: survey evidence on responses of rural households to risk. World Development, 26(1), 89-110.

Kostandini, G., La Rovere, R., \& Abdoulaye, T. (2013). Potential impacts of increasing average yields and reducing maize yield variability in Africa. Food Policy, 43, 213-226.

La Rovere, R., Abdoulaye, T., Kostandini, G., Guo, Z., Mwangi, W., MacRobert, J., \& Dixon, J. (2014). Economic, production and poverty impacts of investing in maize tolerant to drought in Africa. Journal of Developing Areas, 48(1), 199-225.

Li, Y. P., Ye, W., Wang, M., \& Yan, X. (2009). Climate change and drought: a risk assessment of crop-yield impacts. Climate Research, 39, 31-46.

Lunduka, R. (2009). Land rental markets, investment and productivity under customary land tenure systems in Malawi. $\mathrm{PhD}$-dissertation: Department of Economics and Resource Management, Norwegian University of Life Sciences, Ås.

Lunduka, R., Ricker-Gilbert, J., \& Fisher, M. (2013). What are the farmlevel impacts of Malawi's farm input subsidy program? A critical review. Agricultural Economics, 44(6), 563-579.

Magorokosho, C., Vivek, B., MacRobert, J., \& Tarekegne, A. (2010). Characterization of maize germplasm grown in eastern and southern Africa: results of the 2009 regional trials coordinated by CIMMYT. Harare, Zimbabwe: CIMMYT.

Porter, C. (2012). Shocks, consumption, and income diversification in rural Ethiopia. Journal of Development Studies, 48(9), 1209-1222.

Setimela, P. S., MacRobert, J., Atlin, G. N., Magorokosho, C., Tarekegne, A., \& Makumbi, D. (2012). Evaluation of regional on-farm variety trials in eastern and southern Africa 2011. Harare, Zimbabwe: CIMMYT.

Smale, M., \& Jayne, T.S. (2003). Maize breeding in East and Southern Africa, 1900-2000. International Food Policy Research Institute http://ideas.repec.org/p/fpr/2020br/1204.html.

Suri, T. (2011). Selection and comparative advantage in technology adoption. Econometrica, 79, 59-209.

Tambo, J. A., \& Abdoulaye, T. (2013). Smallholder farmers' perceptions of and adaptations to climate change in the Nigerian savanna. Regional Environmental Change, 13, 375-388.

Westengen, O. T., \& Brysting, A. K. (2014). Crop adaptation to climate change in the semi-arid zone in Tanzania: the role of genetic resources and seed systems. Agriculture and Food Security, 3, 1-12. 